\title{
Electron Density Analysis of SARS-CoV-2 RNA-Dependent RNA Polymerase Complexes
}

\author{
Nadezhda Palko *, Maria Grishina * and Vladimir Potemkin *D \\ Laboratory of Computational Modeling of Drugs, Higher Medical and Biological School, \\ South Ural State University, 454080 Chelyabinsk, Russia \\ * Correspondence: palkonn@susu.ru (N.P.); grishinama@susu.ru (M.G.); potemkinva@susu.ru (V.P.)
}

Citation: Palko, N.; Grishina, M.; Potemkin, V. Electron Density

Analysis of SARS-CoV-2

RNA-Dependent RNA Polymerase Complexes. Molecules 2021, 26, 3960 . https://doi.org/10.3390/molecules 26133960

Academic Editors: Maxim

L. Kuznetsov and Alessandro Pedretti

Received: 31 May 2021

Accepted: 25 June 2021

Published: 28 June 2021

Publisher's Note: MDPI stays neutral with regard to jurisdictional claims in published maps and institutional affiliations.

Copyright: (c) 2021 by the authors. Licensee MDPI, Basel, Switzerland. This article is an open access article distributed under the terms and conditions of the Creative Commons Attribution (CC BY) license (https:/ / creativecommons.org/licenses/by/ $4.0 /)$.
Abstract: The work is devoted to the study of the complementarity of the electronic structures of the ligands and SARS-CoV-2 RNA-dependent RNA polymerase. The research methodology was based on determining of 3D maps of electron densities of complexes using an original quantum free-orbital AlteQ approach. We observed a positive relationship between the parameters of the electronic structure of the enzyme and ligands. A complementarity factor of the enzyme-ligand complexes has been proposed. The console applications of the AlteQ complementarity assessment for Windows and Linux (alteq_map_enzyme_ligand_4_win.exe and alteq_map_enzyme_ligand_4_linux) are available for free at the ChemoSophia webpage.

Keywords: SARS-CoV-2; RNA-dependent RNA polymerase; electron density analysis; AlteQ; complementarity

\section{Introduction}

RNA-dependent RNA polymerase (RdRp) is an essential enzyme for the life cycle of RNA viruses [1] and a promising drug target for many viruses, including SARS-CoV2 [2]. Today, the development of safe and effective inhibitors of SARS-CoV-2 RdRp is an important problem. Such compounds should have increased selectivity, while the number of side effects with respect to human host proteins should be minimal. Several studies suggest that drugs targeting RdRp could inhibit SARS-CoV-2 [3-5]. Compounds capable of tightly interacting with the active site of the RdRp are good candidates for research. Strong binding affinity of molecules to RdRp SARS-CoV-2 leads to the impossibility of performing its function and, consequently, to the destruction of the virus [6,7].

Numerous studies have shown that RNA polymerase Inhibitor favipiravir is a promising drug for COVID-19 [8,9]. The antiviral drug favipiravir is a guanidine analogue targeting RdRp viruses [10-12]. Favipiravir is a prodrug. The active form of favipiravir is achieved by phosphoribosylation resulting in the formation of favipiravir-ribofuranosyl- $5^{\prime}$ triphosphate (favipiravir-RTP).

The active form is recognized by RdRp as a purine nucleotide that inhibits the activity of the RdRp enzyme and blocks the synthesis of viral RNA [7]. Recently, Naydenova et al. described the structure of favipiravir ribonucleoside triphosphate (favipiravir-RTP) in complex with the RNA-dependent RNA polymerase SARS-CoV-2. The authors determined that the inhibitor is weakly incorporated into the RNA primer strand and exhibits an unusual, nonproductive binding mode at the catalytic site [8]. At the same time, Peng et al. show another productive binding mode of favipiravir-RTP at the catalytic site of SARS-CoV-2 RdRp [9]. Therefore, several variants of binding to the receptor are proposed for one ligand.

The most important stage in drug action is its interaction with its target. The orientation of the drug in the receptor pocket depends on hydrogen bonds, specific short contacts, and van der Waals interactions with the receptor. All these interactions determine the molecular field, which should ensure complementarity [13] of ligands to receptors. 
The analysis of the electron density distribution allows the identification of non-covalent interactions between the ligand and the receptor [14]. The distribution of the electron density of the outer shells at the ligand-receptor interface is the most important for the formation of the molecular field of covalent bonds and intermolecular contacts.

Niels Bohr formulated the principle of complementarity in 1927 for quantum objects [15]. The concept of complementarity is well-known in physics as the Heisenberg principle [16-18]. In biology and chemistry [19], the principle of complementarity is based on supramolecular interactions, which in turn, are based on the geometric, topological, charge correspondence of molecules or their fragments. A large number of works are devoted to the study of the complementarity of interacting structures. Some of the methods are based on Bader's quantum theory of atoms in molecules (AIM) [20-22], while others propose a method for approximating the molecular surfaces of a cavity by inflating a triangular mesh $[23,24]$. In this article, we propose an alternative method for assessing complementarity based on the AlteQ approach $[25,26]$. The AlteQ approach with good quality describes the experimental electron density which was determined using low temperature high resolution $X$-ray diffraction.

In this paper, we studied the electron density of SARS-CoV-2 RNA-dependent RNA polymerase complexes. The aim of the study was to observe the features of the electronic structure of the complexes, registered experimentally. On the one hand, this work is of fundamental importance - understanding how the electronic structures of the enzyme and ligand should be interconnected to ensure complexation. On the other hand, in the long term, the results of the work can be used to determine the degree of complementarity of new ligands to the presented enzyme.

\section{Materials and Methods}

\subsection{Considered SARS-CoV-2 RNA-Dependent RNA Polymerase Complexes}

SARS-CoV-2 RNA-dependent RNA polymerase complexes were taken from the Protein Data Bank [27]. The complexes were not changed and were taken for computations as they are. RdRp complexes with favipiravir-RTP (7AAP und 7CTT) and with suramin (7D4F) [28] were selected and analyzed (Figure 1). In 7AAP and 7CTT complexes, the favipiravir-RTP ligand has different conformations.

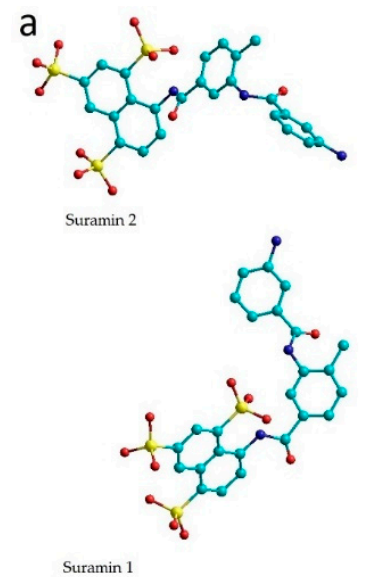

b

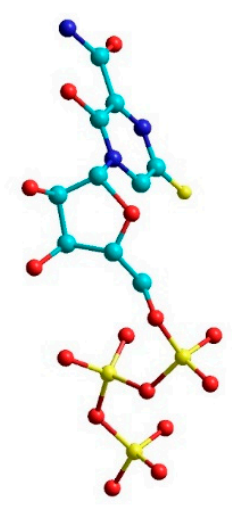

C

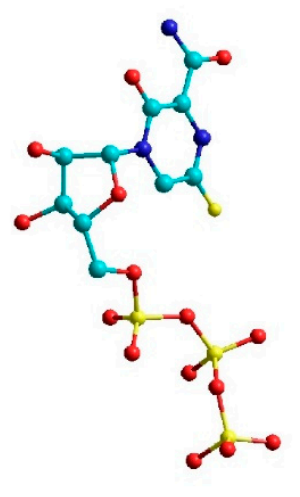

Figure 1. Ligands of 7D4F (a), 7CTT (b) and 7AAP (c) complexes. (colors show: light green-C, yellow-S, red-O, blue-N).

For all complexes, electron density analysis was performed. The calculations were carried out without taking into account hydrogens. 


\subsection{Calculation of 3D Maps of Electron Density}

The calculation of electron density was performed using the improved version of AlteQ method published in [26] in details. AlteQ is an original quantum free-orbital approach, that implements the following principles:

The electron density of molecule is calculated as the sum of atomic contributions at an $m$ th point of molecular space with coordinates $x_{m}, y_{m}, z_{m}$ (Equation (1)),

$$
p\left(x_{m}, y_{m}, z_{m}\right)=\sum_{A=1}^{N} p_{A}
$$

where $N$ is the number of atoms in a molecule, $p_{A}$ is the $\mathrm{A}$ atomic increment in molecular electron density.

The contribution of the electron density of atom A to the molecular electron density is represented as a sum of exponential functions (Equation (2)),

$$
p_{A}=\sum_{i=1}^{n_{A}} a_{A_{i s p}} \exp \left(-b_{A_{i} s p} \cdot R_{A}\right)+\sum_{i=3}^{n_{A}-1} a_{A_{i d}} \exp \left(-b_{A_{i} d} \cdot R_{A}\right)+\sum_{i=4}^{n_{A}-2} a_{A_{i f}} \exp \left(-b_{A_{i} f} \cdot R_{A}\right)
$$

where $a_{A i s p}, b_{A i s p}, a_{A i d}, b_{A i d}, a_{A i f}$ and $b_{A i f}$ are AlteQ atomic parameters describing the $i$-th $s p$-orbital, $d$-orbital and the $f$-orbital of $A$ atom, $n_{A}$ is the period number of the $A$ atom, $R_{A}$ is the distance between the $A$ atomic center and the $m$ th point.

For the outer shells, the electron density can be calculated as follows (Equation (3)).

$$
p_{A(\text { outer })}=a_{A_{n s p}} \exp \left(-b_{\mathrm{nsp}} \cdot R_{A}\right)+a_{A(n-1)_{d}} \exp \left(-b_{A(n-1)_{d}} \cdot R_{A}\right)+a_{A(n-2)_{f}} \exp \left(-b_{A(n-2)_{f}} \cdot R_{A}\right)
$$

The value of electron density of inner shells $\left(p_{A(\text { inner }}\right)$ (Equation (4)) has been estimated as follows:

$$
p_{A(\text { inner })}=p_{A}-p_{A(\text { outer })}
$$

The function $p_{A}$ is based on analysis of the relationship between the logarithm of the experimental electron density derived from the high resolution X-ray diffraction experiment and the distance to the nuclei. AlteQ makes it possible to reconstruct the distribution of electron density in a short time and gaining results, which are very close to the experimental ones. The AlteQ method is especially valuable for studying electron density in large molecular structures, where the electron density analysis is a very time-consuming procedure. The applicability of AlteQ approach for studying large molecular structures has been shown in previous works. AlteQ was used to study the electronic properties of the structures of enzyme-ligand complexes [25,26,29], to study the orders of bonds [30], and photovoltaic properties of dye $-\mathrm{TiO}_{2}$ nanoparticles complexes [31,32].

Since outer shells play the most important role in the enzyme-ligand interactions, we desided to estimate the contribution of the electron density of the outer shell of the enzyme ( $\rho_{E}$, see Equation (5)) and the ligand $\left(\rho_{L}\right.$, see Equation (6)) to the $m$ th point as follows,

$$
\begin{aligned}
& \rho_{E}\left(x_{m}, y_{m}, z_{m}\right)=\sum_{\substack{A=1 \\
A \in \text { enzyme }}}^{N_{\text {enzyme }}} \rho_{\text {Am(outer })} \\
& \rho_{L}\left(x_{m}, y_{m}, z_{m}\right)=\sum_{\substack{A=1 \\
A \in \text { ligand }}}^{N_{\text {ligand }}} \rho_{\text {Am(outer })}
\end{aligned}
$$

where $N_{\text {enzyme }}$ and $N_{\text {ligand }}$ are the numbers of atoms of the ligand and the enzyme.

Intermolecular interactions in the ligand-RdRp system determine the molecular field, which in turn, should ensure the complementarity of the ligand to the receptor. The molecular field is sensitive to changes in intermolecular interactions, caused by ligand movement in the process of interaction with the RdRp. An important parameter characterizing intermolecular interactions is the electron density. The electron density in the region 
of intermolecular interaction can be used to assess the enzyme-ligand complementarity. In this regard, we calculated 3D maps of the electron density for all complexes. In this case, points with an electron density of the receptor and ligand of more than $0.001 \mathrm{au}$. $\left(0.001 \mathrm{e} / \mathrm{Bohr}^{3}\right)$ were considered. This limitation characterizes the boundary of the atom in Bader's theory. The electron density was calculated in the cubic grid with the distance between nearest junctions $0.1 \AA$ (each junction is the $m$ th point) $[29,33,34]$.

\subsection{Complementarity Factor}

For each complex, we observed an empirical dependence described by Equation (7),

$$
f c=a-b \cdot \operatorname{sum} R_{L} R_{E}
$$

where $a$ and $b$ are parameters of the equation.

The parameter fc (Equation (7)) is called complementarity factor. It most effectively describes the relationship of electron densities contributions of the ligand and the receptor at the $m$ th point of the molecular space, was computed. The complementarity factor is expressed through the sum of two contributions provided by the receptor and the ligand (Equation (8)),

$$
f c=\ln \left(\rho_{E} \cdot \frac{\rho_{E C}}{N_{E}}\right)+\ln \left(\rho_{L} \cdot \frac{\rho_{L C}}{N_{L}}\right)
$$

where $\rho_{L C}$ is the electron density of the outer shell in the center of the highest-contributing ligand atom, $\rho_{E C}$ is the electron density of the outer shell in the center of the highestcontributing receptor atom, $N_{L}$ is the atomic number of the highest-contributing ligand atom, and $N_{E}$ is the atomic number of the highest-contributing receptor atom.

The sumR $R_{L} R_{E}$ parameter is the sum of the distances between the $m$ th point and the ligand atom having the highest contribution to $\rho_{L}$ at this point $\left(\mathrm{R}_{\mathrm{L}}\right)$, and the distance between the $m$ th point and the receptor atom having the highest contribution to $\rho_{E}$ at this point $\left(R_{E}\right)$ (Equation $(9)$ ):

$$
\operatorname{sum} R_{L} R_{E}=R_{L}+R_{E}
$$

We have implemented the complementarity assessment in the alteq_map_enzyme_ ligand_4 program for Windows and Linux, now the console applications of the proposed method are publicly available at www.chemosophia.com, accessed on 28 June 2021.

Based on the Equations (7)-(9), we can express the AlteQ complementarity principle as follows (Equation (10)):

$$
\left\{\left(\frac{\rho_{L} \rho_{L C}}{N_{L}}\right) \exp \left(b R_{L}\right)\right\}\left\{\left(\frac{\rho_{E} \rho_{E C}}{N_{E}}\right) \exp \left(b R_{E}\right)\right\}=\exp (a)
$$

We can designate the ligand and the enzyme contributors as $\sigma_{E}$ (Equation (11)), and $\sigma_{L}$ (Equation (12)), respectively:

$$
\begin{aligned}
& \sigma_{E}=\left(\frac{\rho_{E} \rho_{E C}}{N_{E}}\right) \exp \left(b R_{E}\right) \\
& \sigma_{L}=\left(\frac{\rho_{L} \rho_{L C}}{N_{L}}\right) \exp \left(b R_{L}\right)
\end{aligned}
$$

If $R_{L}$ and $R_{E}$ are measured in $\AA, \sigma_{E}$ and $\sigma_{L}$ are measured in e/ $\AA^{6}$.

Then we can get a formula that closely resembles Heisenberg's principle for complementary properties in physics (Equation (13)):

$$
\sigma_{E} \sigma_{L}=\exp (a)
$$


Based on $a$ - and $b$-parameters determined for the experimental complexes, we can reconstruct the pattern of the desired electronic structure of the new promising drug. The pattern can be represented as follows (Equation (14)):

$$
\sigma_{L}=\exp (a) / \sigma_{E}
$$

Further, the actual values $\sigma_{L(\text { new })}$ of a new molecule can be compared with the desired ones $\sigma_{L}$ to ensure maximum similarity. In the case of minimum difference, it is possible to establish the most complementary position of the ligand in the RdRp site.

\subsection{Complementarity Assessment}

Dependencies (Equation (7)), $a$ and $b$ parameters and statistical characteristics (correlation coefficient $\mathrm{R}$, standard error of estimate, standard errors of the $a$ and $b$ parameters, Fisher's criterion) have been found using the method of statistical analysis-Multiple Regression Model. Graphs of the dependencies $f_{c}=f\left(s u m R_{L} R_{E}\right)$ were built using Statistica 13 software [35]. Coordinates of points $m$ of the complementary field with $\rho_{L}>0.001$ a.u. and $\rho_{E}>0.001 \mathrm{a}$.u. and corresponding to the significant overlap of the ligand with the receptor pocket have been printed in pdb files of complexes using our own Windows application uni_coord_one_mol_pdb.exe. The result of visualization using Mercury 3.9 [36] is shown in Figure 2.

a

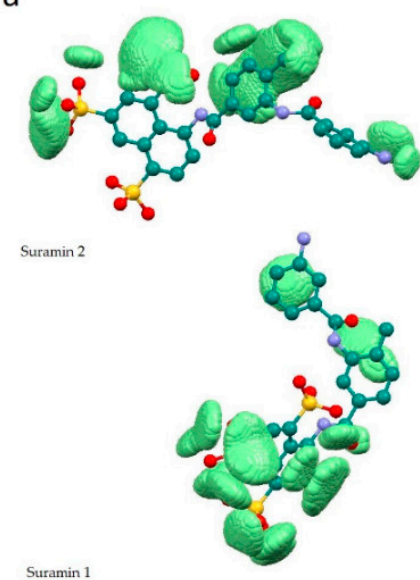

b

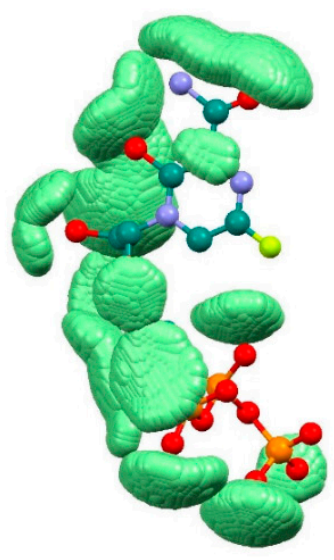

C

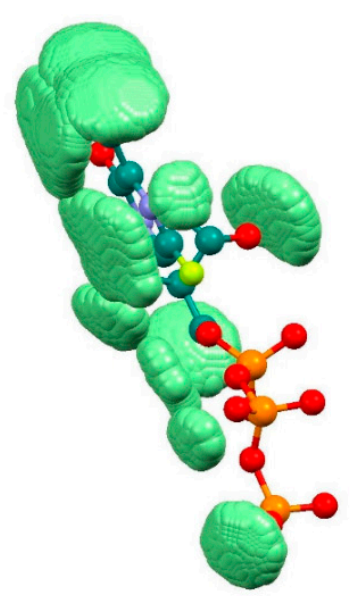

Figure 2. Complementary field (light green) of ligand—receptor complexes. $\left(\rho_{L}>0.001\right.$ a.u. and $\rho_{E}>0.001$ a.u.): (a) $-7 D 4 F$, (b)-7CTT, (c)-7AAP.

\section{Results and Discussion}

Figure 2 demonstrates the localization of zones (the set of considered points $m$ with $\rho_{L}>0.001$ a.u. and $\rho_{E}>0.001$ a.u.) in which there is significant overlap of the ligand with the receptor pocket, near the ligands. In other words, these are zones of space with a receptor and ligand electron density of more than $0.001 \mathrm{au} .\left(0.001 \mathrm{e} / \mathrm{Bohr}^{3}\right)$. In this regard, these zones determine the complementary field of the ligand and receptor in terms of electron density.

We have established that fc correlates with the sum $R_{L} R_{E}$ parameter (Figure 3) very well.

The analysis of the results showed that the character of the dependence of fc on the sum $R_{L} R_{E}$ value for all complexes practically does not change (Figure 3). In all cases, with the decrease of the sum of distances $\left(\operatorname{sum} R_{L} R_{E}\right)$, the overlap of the electron clouds of the ligand and the receptor is enhanced and fc increases. The increase in the factor is associated with a change in the nature of interactions in the system from less effective van der Waals, to more effective specific contacts and hydrogen bonds. The maximum allowable value of the 
complementarity factor should correspond to the contact distances at which, according to the Pauli principle, there is no overlap of the inner electron shells. Therefore, the minimum value of the sum $R_{L} R_{E}$ should also correspond to the absence of overlapping of the inner electron shells. Therefore, the minimal values of $\operatorname{sum}_{\mathrm{L}} R_{\mathrm{E}}$ and maximal values of fc were investigated for all complexes. We found that in all cases, these values ensure that the Pauli principle is met. All complexes are characterized by the absence of overlapping of the inner electron shells; the value of electron density of inner shells $\left(p_{A(\text { inner })}\right)$ does not exceed $10^{-8}$ a.u. in the space of the receptor-ligand overlaps $\left(\rho_{L}>0.001\right.$ a.u. and $\rho_{E}>0.001$ a.u.). The minimal values of sum $R_{L} R_{E}$ and maximal values of $f c$ are different for all complexes. This indicates different types of interactions in the complexes (Figure 4). The 7D4F complex consists of RdRp and two suramin molecules. Intermolecular interaction corresponding to the minimum distance of $2.1 \AA$, is observed only for the second suramin molecule. This is hydrogen bond of one out of three sulfo groups (position 3) of suramin with the guanidine moiety of arginine (Figure 4a). In the 7CTT and 7AAP complexes, the favipiravir-RTP ligand has different conformations and is located differently in the RdRp cavity. In this regard, the interactions between the ligand and the receptor corresponding to the minimum distance are different. In the 7CTT complex, the distance of $2.3 \AA$ corresponds to the interaction between the protease lysine and the favipiravir-RTP triphosphate group (Figure $4 \mathrm{~b}$ ), and in 7AAP, the minimum distance $2.6 \AA$ corresponds to the interaction of the RNA cytosine with the oxygen of the amide group of favipiravir-RTP (Figure 4c). These contacts can be attributed to the most effective interactions that characterize the mechanism of the interactions.
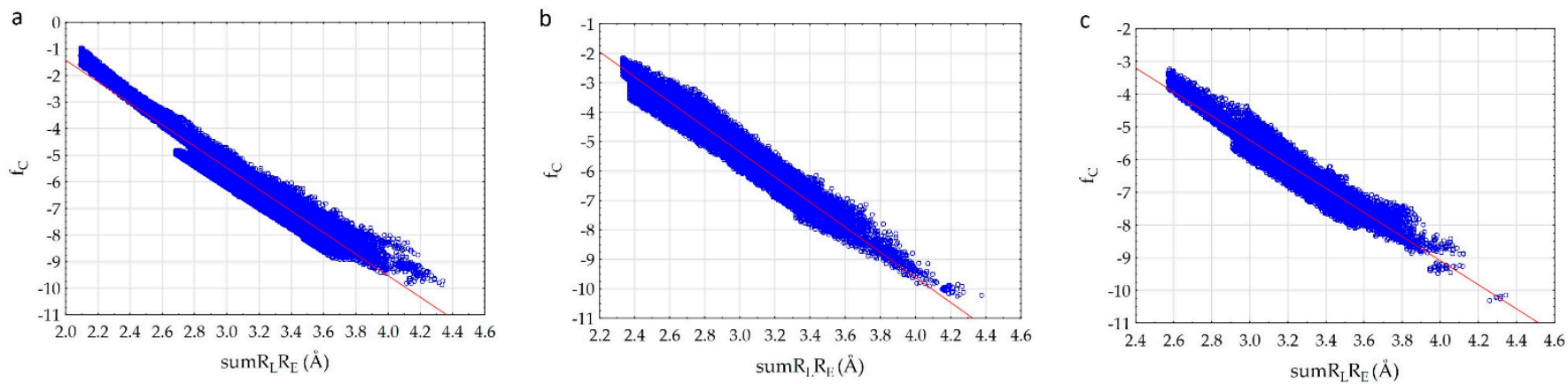

Figure 3. Correlation of the complementarity factor (fc) and the sum of the distances ( $\left.\mathrm{sum}_{\mathrm{L}} \mathrm{R}_{\mathrm{E}}\right)$ : (a) - $7 \mathrm{D} 4 \mathrm{~F}$ (suramin complex), (b)—7CTT (favipiravir-RTP complex), (c)_7AAP (favipiravir-RTP complex).

a

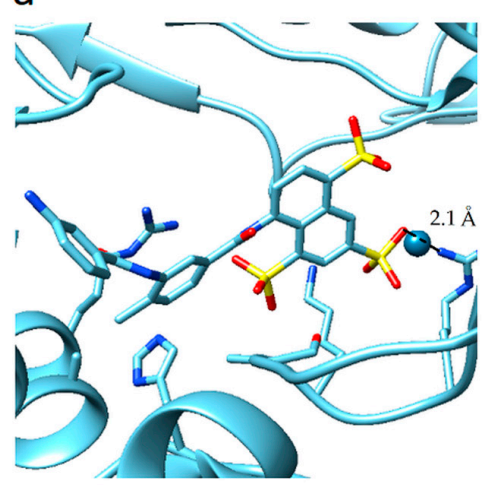

b

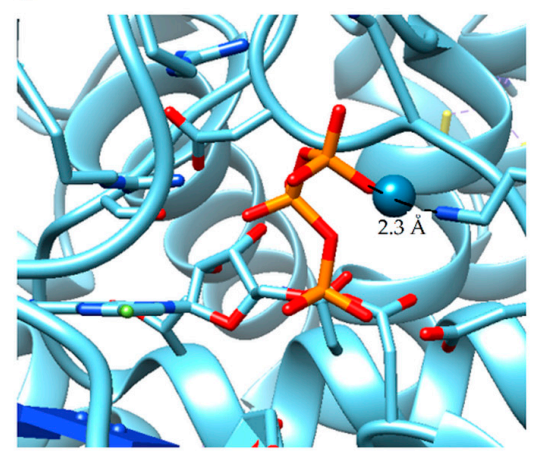

C

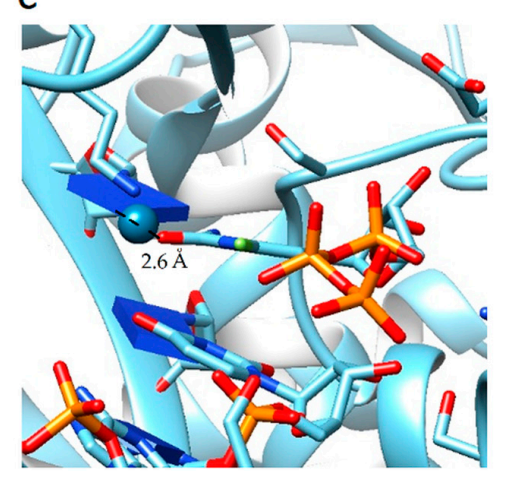

Figure 4. Location of point corresponding to the maximum complementarity factor $(\mathrm{fc})$ for complexes: 7D4F, 7CTT, 7AAP: (a) 7D4F, $2.1 \AA$ is the distance between the sulfo group of suramin and the guanidine component of arginine, (b) 7CTT, $2.3 \AA$ distance between protease lysine and triphosphate group of favipiravir-RTP, (c) 7AAP, $2.6 \AA$ distance between RNA cytosine and oxygen of the amide group of favipiravir-RTP. 
The values of the a-and b-parameters (Equation (7)) determined for the considered complexes, Standard Error for a-and b-parameters (St. Err.), Standard Errors of estimate, Fisher's criterion (F-test), amount of $m$ points and the correlation coefficient $\mathrm{R}$ are presented in Table 1. This information can be used for docking new compounds and select the most promising antiviral agents, which have the most similar electronic structure to the known ligands.

Table 1. Values of the a- and b-parameters, Standard Error for a-and b-parameters (St. Err.), Standard Errors of estimate, Fisher's criterion (F-test), total points and the correlation coefficient R.

\begin{tabular}{ccccccccc}
\hline Complexes & $\mathbf{a}$ & $\begin{array}{c}\text { St. Err. } \\
\mathbf{a}\end{array}$ & $\mathbf{b}$ & $\begin{array}{c}\text { St. Err. } \\
\mathbf{b}\end{array}$ & $\begin{array}{c}\text { St. Err. of } \\
\text { Estimate }\end{array}$ & F-Test & $\begin{array}{c}\text { Amount of } \\
\boldsymbol{m} \text { Points }\end{array}$ & $\begin{array}{c}\text { R } \\
\text { 7D4F }\end{array}$ \\
\hline 7CTT & 6.683 & 0.017 & 4.0547 & 0.0052 & 0.35 & 600340 & 33838 & 0.973 \\
7AAP & 7.406 & 0.018 & 4.2539 & 0.0059 & 0.30 & 522541 & 25622 & 0.976 \\
\hline
\end{tabular}

An analysis of the results showed that the a- and b-parameters are different for all complexes and depend on the atoms involved in intermolecular interactions. The correlation coefficients of the dependencies are 0.966-0.973. Therefore, we can presuppose that the whole proposed principle of complementarity lies precisely in the fact that from the entire set of atoms of the enzyme and the ligand, only a pair of the enzyme and the ligand atoms which make the most significant contribution to the electron density at the $m$ th point can be isolated. This provides a high correlation of the complementarity factor and sum $R_{L} R_{E}$ value. In the case when two or more atoms make a significant contribution to the $m$ th point, the dependence should worsen, and the correlation coefficient should decrease. Therefore, in the considered complexes, the interactions between the enzyme and the ligand are carried out in such a way that the pair atom-atom interactions are mainly observed and the number of bifurcate intermolecular bonds is minimized. Based on the correlation coefficients, it can be concluded that the 7CTT complex is characterized by a slightly higher complementarity of RdRp and ligand compared to the 7D4F and 7AAP complexes. This model provides the monotonic increase in the electron density overlap with decreasing intermolecular distance, taking into account the entire spectrum of intermolecular interactions from weak van der Waals to strong hydrogen bonds. Indeed, a comparison of the graphs of dependences for various complexes showed that for the 7CTT complex the dependence is more uniform. The graph width is highly dependent on the variety of ligand and receptor contacts. The 7D4F complex is characterized by less diverse contacts and the ligand of 7D4F complex interacts with a smaller number of the receptor atoms than ligands of 7CTT and 7AAp complexes.

Complexes 7CTT and 7AAP have the same ligand-favipiravir-RTP, but the graphs of dependences differ. We decided to determine the reason for the found difference. For this, we analyzed the structure of the 7CTT and 7AAP complexes. The molecular field of the ligand is complementary to the molecular field of the receptor. In the 7CTT and 7AAP complexes, the favipiravir-RTP is surrounded by RNA and enzyme. Each subunit has its own molecular field. Then, the molecular field of the receptor will be defined as a superposition of the subunit fields, and the ligand field should be complementary to both RNA and enzyme fields. To determine the most effective binding of the molecule to the receptor, a comparative analysis of the relationship between the complementarity factor and sumR $R_{\mathrm{L}} \mathrm{R}_{\mathrm{E}}$ in the ligand complexes with each RdRp subunit was carried out; "ligand-RNA" and "ligand-enzyme" interactions were considered separately. Analysis was performed for both 7CTT and 7AAP complexes. As a result, it was found that in all cases there is a linear increase of $f c$ with a decrease of sum $R_{L} R_{E}$. In this case, the plots for the 7CTT and 7AAP structures differ quite strongly (Figure 5). This feature indicates a strong effect of the conformational state of the ligand on the complementarity. 
a

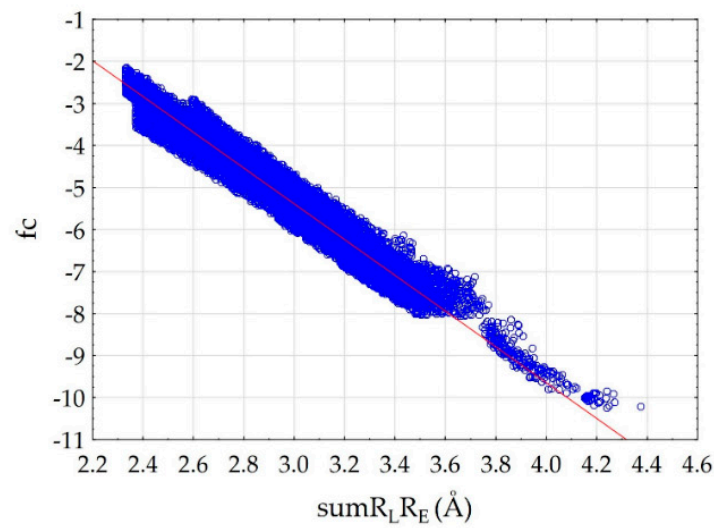

c

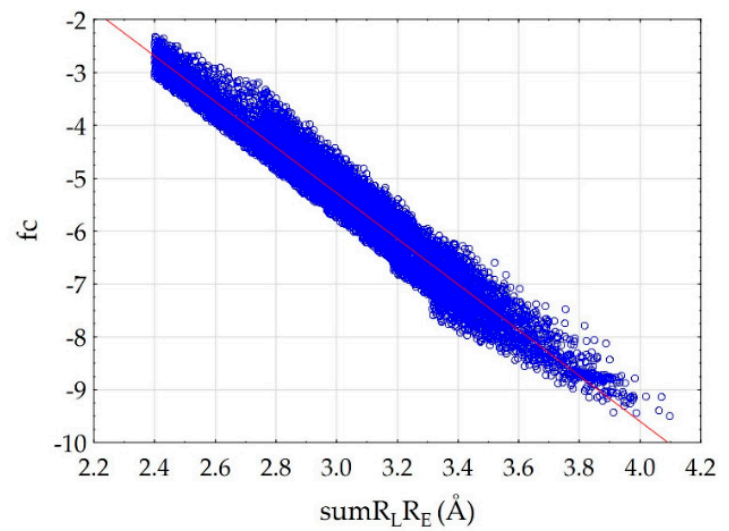

b

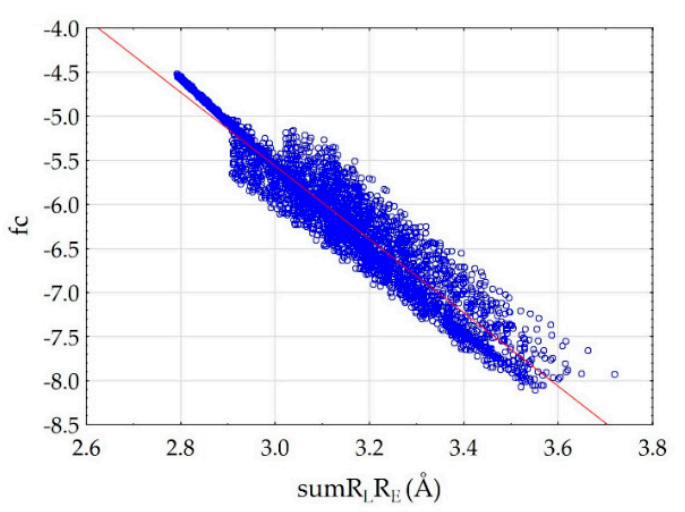

d

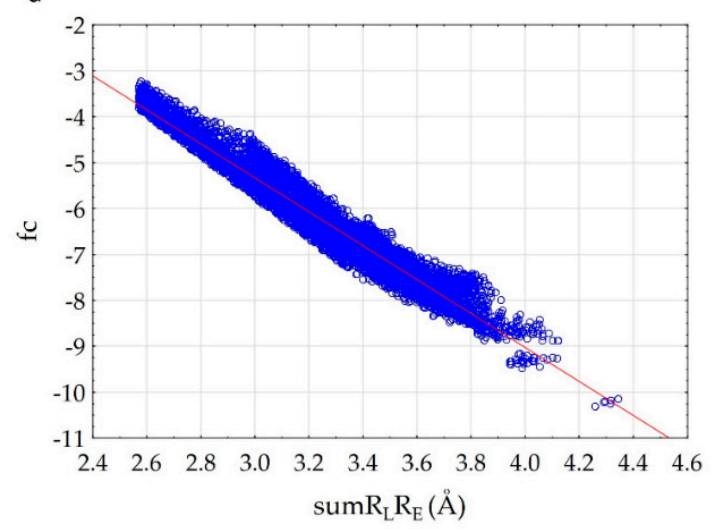

Figure 5. Correlation of complementarity factor $\left(f_{c}\right)$ with the sum of the distances $\left(s u m R_{L} R_{E}\right)$ : 7CTT enzyme-favipiravirRTP (a), 7AAP enzyme—favipiravir-RTP (b), 7CTT RNA—favipiravir-RTP (c), 7AAP RNA—favipiravir-RTP (d).

The shape of the graph $f c=f\left(s u m R_{L} R_{E}\right)$ for "ligand-enzyme" interactions is more uniform for the 7CTT complex as compared to the 7AAP complex. For 7AAP complex, a narrow band is observed on the graph for sum $R_{L} R_{E} 2.8-3.0 \AA$, and after reaching $3.0 \AA$, the narrow band becomes wide and loose. This kind of uneven change in the fc indicates that for different sum $R_{L} R_{E}$, different numbers of atoms are involved in the intermolecular interactions. The complementary fields of 7CTT enzyme and 7AAP enzyme with favipiravir-RTP are shown in Figure 6a,b. In contrast to the enzyme-ligand interactions of the 7CTT and 7AAP complexes, the RNA-ligand interactions of these complexes are more similar. In this case, a monotonic increase in the descriptor with a decrease in sumR $R_{L} R_{E}$ is observed. This indicates a uniform overlap of the electron clouds of the ligand with the RNA at each $m$ th point. Thus, the favipiravir-RTP conformation observed in the 7CTT complex is complementary to both RNA and the enzyme (Figure 6). In the case of the favipiravir-RTP (7AAP) conformation, it can be noted that the ligand interacts more efficiently with RNA than with the enzyme. 


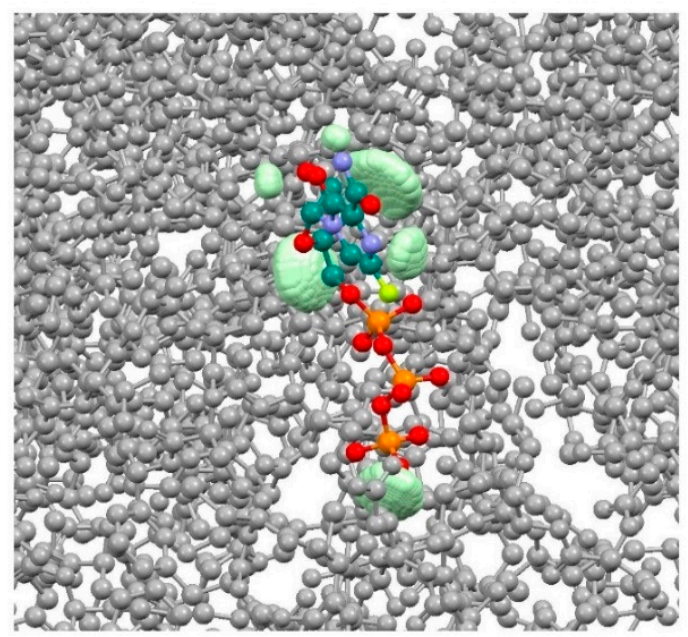

C

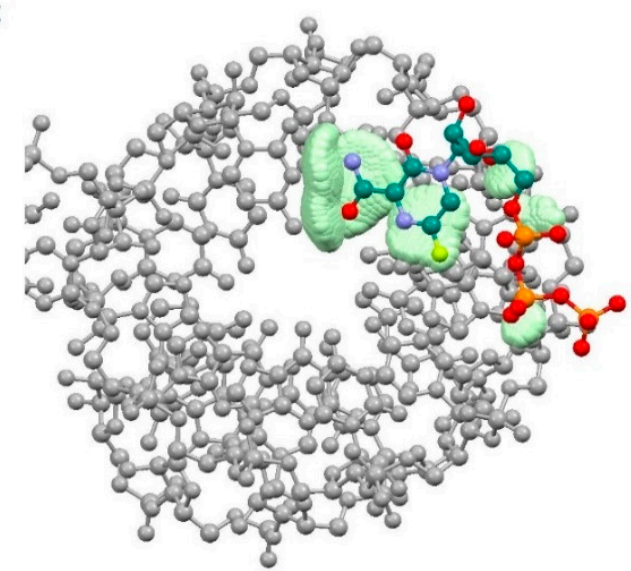

b

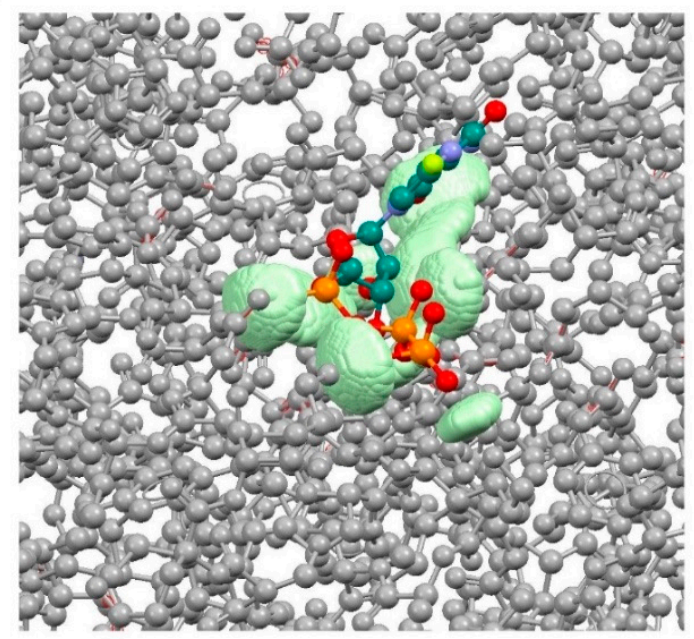

d

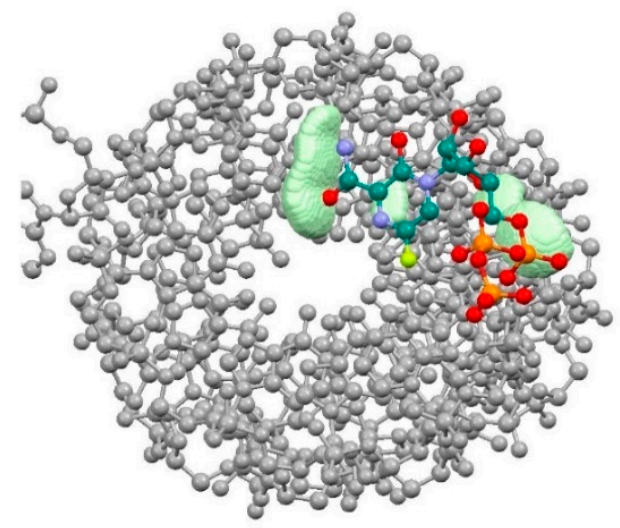

Figure 6. Complementary field of complexes 7CTT and 7AAP: 7AAP enzyme-favipiravir-RTP (a), 7CTT enzymefavipiravir-RTP (b), 7AAP RNA—favipiravir-RTP (c), 7CTT RNA—favipiravir-RTP (d) (grey—enzyme (a,b) and RNA (c,d), light green-complementary field).

Correlation coefficients $\mathrm{R} 1$, as well as c- and d-parameters of the equation $f c=f\left(\operatorname{sum} R_{L} R_{E}\right)$ for "enzyme-ligand" and "RNA-ligand" interactions of 7CTT and 7AAP complexes are shown in Table 2.

Table 2. Values of the c- and d-parameters, Standard Error for c- and d-parameters (St. Err.), Standard Errors of estimate, Fisher's criterion (F-test), amount of $m$ points and the correlation coefficient R1 for complexes 7CTT and 7AAP.

\begin{tabular}{ccccccccc}
\hline Complexes & c & $\begin{array}{c}\text { St. Err. } \\
\text { c }\end{array}$ & d & $\begin{array}{c}\text { St. Err. } \\
\mathbf{d}\end{array}$ & $\begin{array}{c}\text { St. Err. of } \\
\text { Estimate }\end{array}$ & F & $\begin{array}{c}\text { Amount } \\
\text { of } \\
m \text { Points }\end{array}$ & R1 \\
\hline $\begin{array}{c}\text { 7CTT } \\
\text { enzyme-L }\end{array}$ & 7.365 & 0.021 & 4.2531 & 0.0070 & 0.30 & 373456 & 17060 & 0.978 \\
7CTT RNA-L & 7.697 & 0.033 & 4.326 & 0.011 & 0.32 & 165549 & 8481 & 0.975 \\
\hline $\begin{array}{c}\text { 7AAP } \\
\text { enzyme-L }\end{array}$ & 6.954 & 0.074 & 4.172 & 0.024 & 0.24 & 31314 & 3286 & 0.951 \\
7AAP RNA-L & 5.755 & 0.028 & 3.6953 & 0.0086 & 0.27 & 185132 & 8829 & 0.977 \\
\hline
\end{tabular}

The results presented in the Table 2 confirm the stronger complementarity of the "ligand-RdRp" in the 7CTT structure than in the 7AAP complex. The correlation coefficient R1, as well as c- and d-parameters obtained for the structures 7CTT and 7AAP 
show that the maximum complementarity of the ligand to the enzyme is achieved only if the ligand is complementary to all structural subunits of the receptor, namely RNA and the enzyme. The results obtained can be used to establish the reliability of docking of new structures.

\section{Conclusions}

In this article, a study of complementarity in the SARS-CoV-2 RNA-dependent RNA polymerase complexes with ligands was carried out. The complementarity assessment was based on the overlap of the electron clouds of the ligand and the receptor. The electron density was calculated using the original quantum free-orbital AlteQ approach. We have determined the complementarity factor relating to electron density contributions of the ligand and the receptor to each other. The relationship between the complementarity factor and the sum of the distances between contacting atomic centers has been established. It was found that the maximum complementarity of the ligand to the RdRp is achieved in the case of the complementarity of the ligand to both RNA and enzyme subunits of the receptor. The results can be used to predict biological activity, molecular docking, as well as to study the mechanism of drug action. Equations describing complementarity can be used to assess the correct binding pose of a new ligand to the receptor by comparing aand b-parameters of the equation, correlation coefficient or standard error of estimate of modeled complexes with the data found in the current work.

Author Contributions: Conceptualization, N.P., M.G., V.P.; methodology, N.P., M.G., V.P.; software, M.G., V.P.; investigation, N.P.; writing-original draft preparation, N.P.; data curation, M.G., V.P.; writing-review and editing, N.P., M.G., V.P.; funding acquisition, V.P. All authors have read and agreed to the published version of the manuscript.

Funding: The reported study was funded by RFBR, DST, CNPq, SAMRC, project number 20-53-80002.

Institutional Review Board Statement: Not applicable.

Informed Consent Statement: Not applicable.

Data Availability Statement: Publicly available datasets were analyzed in this study. This data can be found here: www.chemosophia.com.

Conflicts of Interest: The authors declare no conflict of interest.

\section{References}

1. Zanotto, P.M.; Gibbs, M.J.; Gould, E.A.; Holmes, E.C. A reevaluation of the higher taxonomy of viruses based on RNA polymerases. J. Virol. 1996, 70, 6083. [CrossRef]

2. Tian, L.; Qiang, T.; Liang, C.; Ren, X.; Jia, M.; Zhang, J.; Li, J.; Wan, M.; Yu Wen, X.; Li, H.; et al. RNA-dependent RNA polymerase (RdRp) inhibitors: The current landscape and repurposing for the COVID-19 pandemic. Eur. J. Med. Chem. 2021, 213. [CrossRef]

3. Ju, J.; Li, X.; Kumar, S.; Jockusch, S.; Chien, M.; Tao, C.; Morozova, I.; Kalachikov, S.; Kirchdoerfer, R.N.; Russo, J.J. Nucleotide analogues as inhibitors of SARS-CoV Polymerase. Pharmcol. Res. Perspect. 2020. [CrossRef] [PubMed]

4. Vicenti, I.; Zazzi, M.; Saladini, F. SARS-CoV-2 RNA dependent RNA polymerase as a therapeutic target for COVID-19. Expert Opin. Ther. Pat. 2021. [CrossRef] [PubMed]

5. $\quad$ Baby, K.; Maity, S.; Mehta, C.H.; Suresh, A.; Nayak, U.Y.; Nayak, Y.; Holla, H.; Reddy, H. Targeting SARS-CoV-2 RNA-dependent RNA polymerase: An in silico drug repurposing for COVID-19. F1000Research 2020. [CrossRef]

6. Elfiky, A.A. SARS-CoV-2 RNA dependent RNA polymerase (RdRp) targeting: An in silico perspective. J. Biomol. Struct. Dyn. 2020. [CrossRef] [PubMed]

7. Zhu, W.; Chen, C.Z.; Gorshkov, K.; Xu, M.; Lo, D.C.; Zheng, W. RNA-Dependent RNA Polymerase as a Target for COVID-19 Drug Discovery. SLAS Discov. 2020, 25, 1141-1151. [CrossRef]

8. Naydenova, K.; Muir, K.W.; Wu, L.-F.; Zhang, Z.; Coscia, F.; Peet, M.J.; Castro-Hartmann, P.; Qian, P.; Sader, K.; Dent, K.; et al. Structure of the SARS-CoV-2 RNA-dependent RNA polymerase in the presence of favipiravir-RTP. Proc. Natl. Acad. Sci. USA 2021, 118, e2021946118. [CrossRef]

9. Peng, Q.; Peng, R.; Yuan, B.; Wang, M.; Zhao, J.; Fu, L.; Qi, J.; Shi, Y. Structural basis of SARS-CoV-2 polymerase inhibition by Favipiravir. Innovation 2021, 2, 100080. [CrossRef]

10. Du, Y.X.; Chen, X.P. Favipiravir: Pharmacokinetics and Concerns About Clinical Trials for 2019-nCoV Infection. Clin. Pharmacol. Ther. 2020, 108, 242-247. [CrossRef] 
11. Shiraki, K.; Daikoku, T. Favipiravir, an anti-influenza drug against life-threatening RNA virus infections. Pharmacol. Ther. 2020, 209, 107512. [CrossRef] [PubMed]

12. Furuta, Y.; Takahashi, K.; Fukuda, Y.; Kuno, M.; Kamiyama, T.; Kozaki, K.; Nomura, N.; Egawa, H.; Minami, S.; Watanabe, Y.; et al. In vitro and in vivo activities of anti-influenza virus compound T-705. Am. Soc. Microbiol. J. 2002, 46, 977-981. [CrossRef]

13. Bohr, N. On the notions of causality and complementarity. Dialectica 1948, 2, 312-319. [CrossRef]

14. Bader, R.F.W. Atoms in Molecules. A Quantum Theory; Oxford University Press: Oxford, UK, 1990.

15. Bohr, N. Atomic Theory and the Description of Nature; Cambridge University Press: Cambridge, UK, 1934.

16. Guth, E. Gruppentheorie und Quantenmechanik. Mon. Math. Phys. 1929, 36, A48-A52. [CrossRef]

17. Kennard, E.H. Zur Quantenmechanik einfacher Bewegungstypen. Z. Phys. 1927, 44, 326-352. [CrossRef]

18. Heisenberg, W. Über den anschaulichen Inhalt der quantentheoretischen Kinematik und Mechanik. Z. Phys. 1927, 43, 172-198. [CrossRef]

19. Ehrlich, P. Croonian Lecture-On Immunity with Special Reference to Cell Life. Proc. R. Soc. Lond. 1900, 66, 424-448. [CrossRef]

20. Matta, C.F.; Arabi, A.A.; Weaver, D.F. The bioisosteric similarity of the tetrazole and carboxylate anions: Clues from the topologies of the electrostatic potential and of the electron density. Eur. J. Med. Chem. 2010, 45, 1868-1872. [CrossRef]

21. Matta, C.F.; Arabi, A.A. Electron-density descriptors as predictors in quantitative structure-activity/property relationships and drug design. Future Med. Chem. 2011, 3, 969-994. [CrossRef]

22. Oloff, S.; Zhang, S.; Sukumar, N.; Breneman, C.; Tropsha, A. Chemometric analysis of ligand receptor Complementarity: Identifying Complementary Ligands Based on Receptor Information (CoLiBRI). J. Chem. Inf. Modeling 2006, 46, 844-851. [CrossRef]

23. Cai, C.; Gong, J.; Liu, X.; Jiang, H.; Gao, D.; Li, H. A novel, customizable and optimizable parameter method using spherical harmonics for molecular shape similarity comparisons. J. Mol. Modeling 2012, 18, 1597-1610. [CrossRef] [PubMed]

24. Cai, W.; Shao, X.; Maigret, B. Protein-ligand recognition using spherical harmonic molecular surfaces: Towards a fast and efficient filter for large virtual throughput screening. J. Mol. Graph. Model. 2002, 20, 313-328. [CrossRef]

25. Potemkin, V.A.; Grishina, M.A. A new paradigm for pattern recognition of drugs. J. Comput. Aided Mol. Des. 2008, 22, 489-505. [CrossRef] [PubMed]

26. Grishina, M.A.; Potemkin, V.A. Topological Analysis of Electron Density in Large Biomolecular Systems. Curr. Drug Discov. Technol. 2019, 16, 437-448. [CrossRef]

27. RCSB PDB: Homepage. Available online: https://www.rcsb.org/ (accessed on 10 December 2020).

28. Yin, W.; Luan, X.; Li, Z.; Zhou, Z.; Wang, Q.; Gao, M.; Wang, X.; Zhou, F.; Shi, J.; You, E.; et al. Structural basis for inhibition of the SARS-CoV-2 RNA polymerase by suramin. Nat. Struct. Mol. Biol. 2021, 28, 319-325. [CrossRef]

29. Rimac, H.; Grishina, M.A.; Potemkin, V.A. Electron density analysis of CDK complexes using the AlteQ method. Future Med. Chem. 2020, 12, 1387-1397. [CrossRef] [PubMed]

30. Salmina, E.; Grishina, M.A.; Potemkin, V.A. An approximation of the Cioslowski-Mixon bond order indexes using the AlteQ approach. J. Comput. Aided Mol. Des. 2013, 27, 793-805. [CrossRef]

31. Potemkin, V.; Palko, N.; Grishina, M. Quantum theory of atoms in molecules for photovoltaics. Sol. Energy 2019, 190, 475-487. [CrossRef]

32. Grishina, M.; Bolshakov, O.; Potemkin, A.; Potemkin, V. Theoretical investigation of electron structure and surface morphology of titanium dioxide anatase nano-particles. Comput. Theor. Chem. 2016, 1091, 122-136. [CrossRef]

33. Rimac, H.; Grishina, M.; Potemkin, V. Use of the Complementarity Principle in Docking Procedures: A New Approach for Evaluating the Correctness of Binding Poses. J. Chem. Inf. Model. 2021, 61, 27. [CrossRef]

34. Kandagalla, S.; Rimac, H.; Grishina, M.; Potemkin, V. Complementarity principle in terms of electron density for the study of EGFR complexes. Future Med. Chem. 2021, 13, 863-875. [CrossRef] [PubMed]

35. TIBCO Software Inc. Statistica (Data Analysis Software System), Version 13. 2017. Available online: http: / / statistica.io (accessed on 14 February 2019).

36. Mercury 3.9 (Build RC1). Available online: http://www.ccdc.cam.ac.uk/mercury/ (accessed on 5 August 2019). 